\title{
Treatment of grade III furcation lesion by tunneling in a smoker pa- tient: Clinical Case Report
}

Francesco Saverio Ludovichetti', Guilherme José Pimentel Lopes de Oliveira², Joni Augusto Cirelli².

${ }^{1}$ Department of Neurosciences, Dentistry Section, University of Padova, Via Giustiniani, 1, 35131 Padova, Italy. ${ }^{2}$ Department of Diagnosis and Surgery, School of Dentistry at Araraquara, Univ. Est. Paulista, Araraquara, Brazil.

\begin{abstract}
Objective: The aim of this study is to describe a case report of lower molar treatment with grade III furcation by the tunneling technique in a heavy smoker patient. Case presentation: In the present study, a 40-year-old man, a heavy smoker (> 20 cigarettes / day) presented a grade III furcation injury on dental element 46 after a clinical and radiographic examination. After non-surgical periodontal therapy, the patient was treated with the execution of the tunneling of the furcation of the tooth 46, which was effective in the control of the disease and in the maintenance of the dental element after 12 months of follow up. Final considerations: The tunneling technique was effective in the control of periodontal disease in a heavy smoking patient, with a good standard of hygiene and motivation, and good clinical results were maintained after 12 months of follow-up.
\end{abstract}

Keywords: Furcation defects; Dental scaling; Implant; Periodontal; Modelling.

\section{Introduction}

Periodontitis is a multifactorial inflammatory disease caused by a polymicrobial infection that affects the support tissues of the periodontal insertion, and if not controlled, can lead to bone loss that can culminate with tooth loss ${ }^{1}$. When the prognosis of periodontal disease progresses in the molar teeth, it is common for the involvement of the furcation regions to occur, which impairs the prognosis of these dental elements ${ }^{2}$. In fact, it has been shown that teeth with furcation are the most lost in patients in periodontal support therapy and because of this, teeth with a worse prognosis are considered regarding the outcome of periodontal therapy ${ }^{3}$.

Thus, it is not uncommon to recommend the extraction of teeth with furcation involvement for subsequent dental implants. However, although osseointegration is successfully achieved in a large part of the treated population, such as predictability, survival and success, certain groups of patients, such as heavy smokers and decompensated diabetics have lower success rates for implant supported prostheses and obtaining osseointegration ${ }^{4}$. In these cases, it may be interesting to maintain the dental element instead of attempting to replace it with an osseointegrated implant.

For cases of furcation involvement, a range of treatments have been proposed depending on the severity of the injury. Specifically, in grade III furcation lesions, root resection ${ }^{5}$, scaling with open flap 6 and tunneling ${ }^{7}$ may be chosen. All of these treatments would have the objective of obtaining access to the furcation region for removal of the biofilm by the professional and the patient. Resection is commonly used when one of the dental roots is involved ${ }^{5}$, while tunneling is indicated for grade III furcation lesions in lower molar teeth with a short root trunk, where an odontoplasty is performed with posterior exposure of the furcation ceiling to the oral medium, which allows the patient to sanitize this region with greater efficiency? ${ }^{7}$. The present case report describes the tunneling technique in a lower molar of a heavy smoker patient,

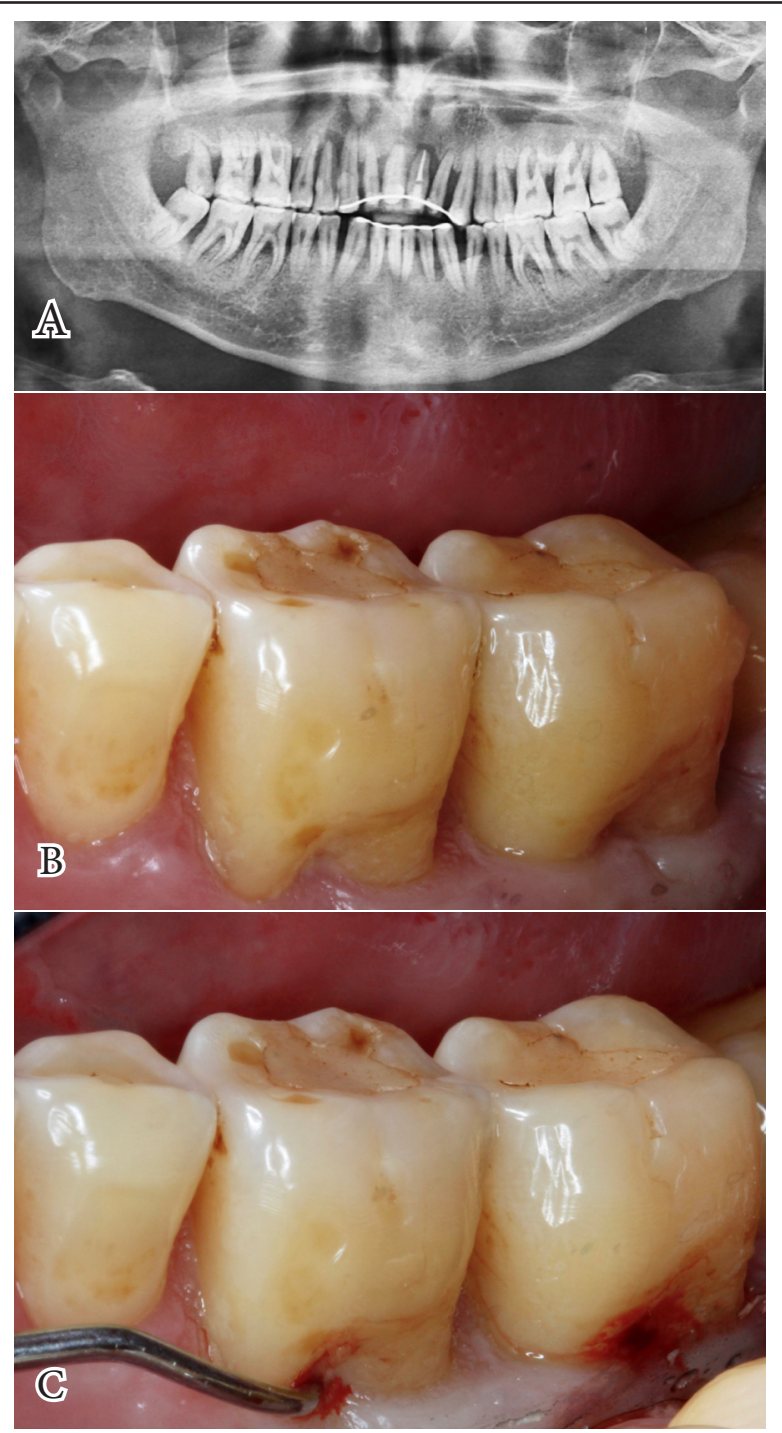

Figura 1 - Furcation lesion diagnosis: (A) Preoperative panoramic radiography. Note the associated radiolucency and tooth furcation region 46; (B) Preoperative aspect of the tooth 46 where it is possible to verify the vestibular root exposition; (C) Probing of the furcation lesion with presence of bleeding on probing. In this examination, it was possible to confirm the involvement of the furcation grade III. 
as well as describing the clinical success observed after one year of performing the surgical procedure.

\section{Case Report}

A 40-year-old adult male patient was treated at the Periodontics specialization clinic of the Araraquara Dental School (Foar-Unesp). The patient was a heavy smoker (> 20 cigarettes per day) and presented bleeding with generalized probing, dental mobility and gre-
Curettes 1-2, 3-4, 5-6. Millennium-Golgran, São Paulo (SP) Brazil) with open field where calculus and granulation tissue were removed. Subsequently, an osteoplasty was performed in the bone tissue medially and distally from the furcation region to create a more harmonious anatomy that would allow an easier access to perform the hygiene of the area by the patient. Finally, the flap was sutured to the bone level (Silk, Ethicon 4.0, Johnson \& Johnson Medical, New Brunswick, New
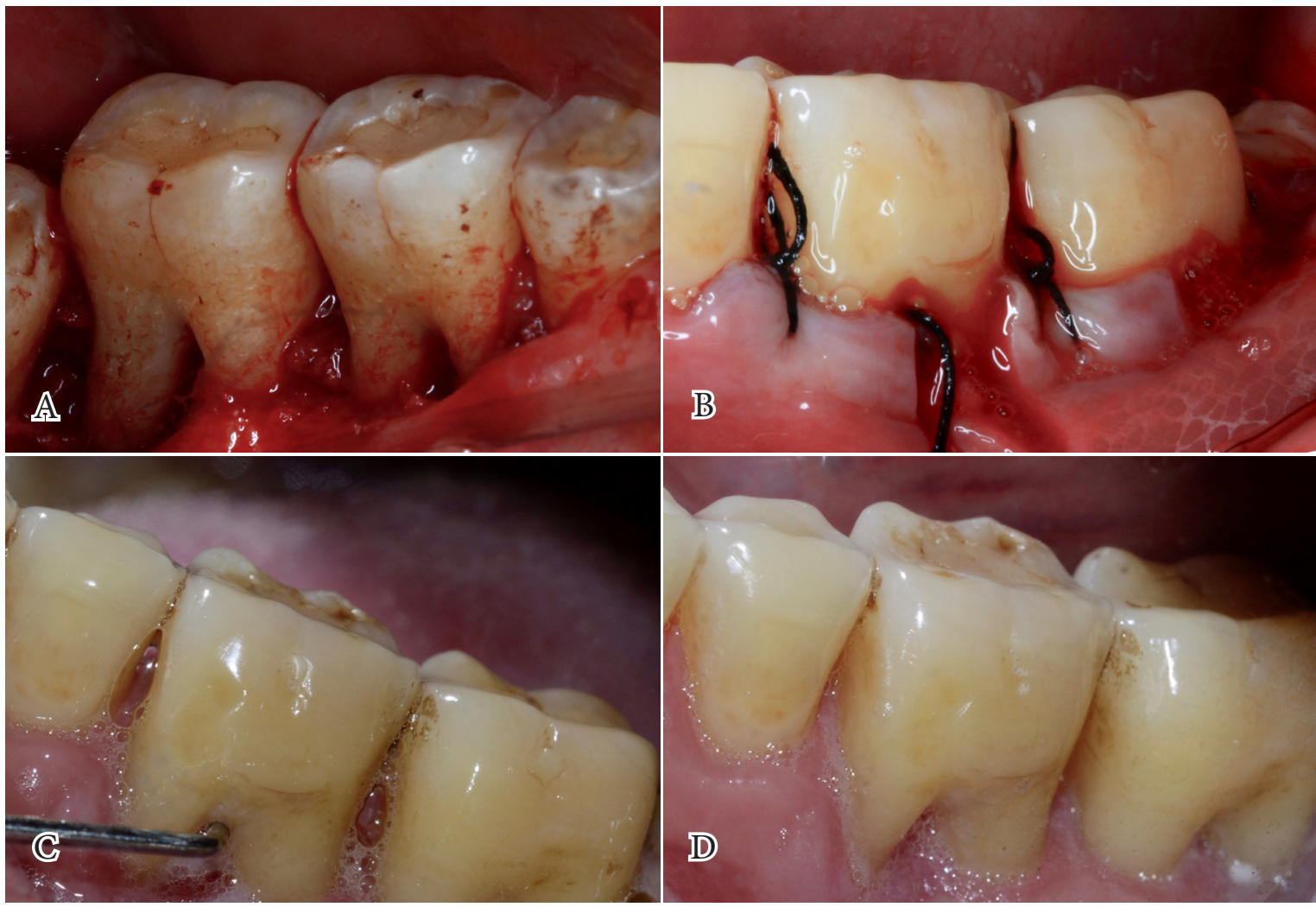

Figure 2 - Operative procedure and follow-up: (A) Retracted flaps and bone tissue associated with the roots of the 46 after the plasty procedure; (B) Sutured and apically repositioned flap with the intention of exposing the furcation of the element 46 to the oral environment; (C) Clinical situation 1 month after the surgical procedure with exposure of the furcation to the oral environment due to the tunneling procedure; (D) Clinical situation after 12 months of follow-up, where it is possible to notice the clinical stability of the tooth 46 .

at presence of periodontal pockets. The probing depth was measured, considering the distance from the gingival margin to the most apical position of the probe, in six sites of the tooth: mesio-vestibular $(5 \mathrm{~mm})$, medio-vestibular ( $5 \mathrm{~mm})$, disto-vestibular (7 mm), mesio-lingual (5 $\mathrm{mm})$, medio-lingual $(5 \mathrm{~mm})$, and disto-lingual $(7 \mathrm{~mm})$.

After the clinical and radiographic examinations, it was verified that the patient presented a grade III furcation lesion in the dental element 46 (Figure 1 A-B-C). First, non-surgical periodontal therapy was planned to reduce inflammation, bleeding, and depth of the periodontal pocket. After this phase of the treatment, the execution of the tunneling of the furcation of the tooth 46 was planned. After local anesthesia, a total flap was performed associated with the buccal and lingual surfaces in order to apically reposition the flap (Figure 2 A). Next, scaling and root planing with hand instruments was performed (Gracey Curettes 7-8,11-12 and 13-14, and PL
Jersey USA), displaced apically for exposure to the furcation region (Figure $2 \mathrm{~B}$ ). The suture was removed 7 days after surgery. An anti-inflammatory (Nimesulide 100mg, 2 times a day for 3 days), analgesic (Dipirone $500 \mathrm{mg}$, 1 tablet every 8 hours for 3 days), and $0.12 \%$ chlorhexidine was prescribed during the post-operative and complete oral hygiene instruction was furnished. At 1 month return, the patient was already presenting good healing and oral hygiene levels (Figure $2 \mathrm{C}$ ).

At 12 months' return, the patient was presented with stability of the lesion, with no bleeding on probing, cavities or loss of insertion (Figure $2 \mathrm{D}$ ). The probing depth was measured again in six sites of the tooth: mesio-vestibular ( $3 \mathrm{~mm})$, medio-vestibular (3 $\mathrm{mm})$, disto-vestibular (5 mm), mesio-lingual (3 $\mathrm{mm})$, medio-lingual $(3 \mathrm{~mm})$, and disto-lingual $(5 \mathrm{~mm})$. It was also possible to observe that the patient presented a good level of hygiene at that moment, however, the heavy smoke habit remained unchanged. 


\section{Discussion}

Furcation lesions have been considered a challenge for periodontal treatment because it is a therapy of poorly predictable clinical results and because the teeth are more lost during periodontal support thera$\mathrm{py}^{3}$, thus being a classic indication for replacement of this dental element by a prosthesis supported by an osseointegrated implant ${ }^{8}$. However, even today there are several factors that can lead to the choice of periodontal therapy to maintain the tooth instead of replacing it with a dental implant, such as economic reasons, the patient's desire to maintain the tooth and the presence of systemic diseases or behavior that leaves the patient at risk of failure for implant therapy ${ }^{9}$ (9).

In the case presented, the choice for dental maintenance was due to the patient's desire to maintain the dental element and because the patient was a heavy smoker. Previous clinical studies have shown that the success rate of implants installed in smokers can vary from $65.3 \%$ to $97 \%$, which is lower than that found in patients without this habit, where success can range from $82.7 \%$ to $98.8 \%{ }^{10}$. It has also been verified that a smoking status negatively influences bone regeneration and that bone regeneration techniques are less effective in smoking patients when compared to patients who do not have this habit ${ }^{11}$.

Since the two therapies do not have great predictability in smoking patients, as was our case, it is prudent to attempt to maintain the dental element in heavy smoking patients in order to avoid surgical therapy with this patient. Since the tooth presented no sign of sensitivity and the patient was carefully motivated and trained in oral hygiene practice, it was decided to carry out a tunneling procedure associated with open scaling to facilitate the removal of the dental calculus in the furcation region which has been shown to improve the outcome of the treatment in relation to the execution of scaling in the closed field ${ }^{12}$. Another treatment could be indicated for this clinical condition such as the application of scaling and root planning isolated or associated the regenerative techniques. The absence of an attempt to perform regenerative techniques is due to the high impressibility of therapeutic success in grade III furcation lesions ${ }^{13}$. It has been showed that class III furcation lesions treated by scaling and root planning or associated with regenerative techniques rarely closed completely, and thus, the prognosis of these teeth does not improve after the application these treatments ${ }^{14}$.

Although the tunneling technique provides greater access to cleansing of the furcation region, on the other hand, there is a greater risk of caries formation in the root. In fact, a study evaluating the incidence of caries in molars that underwent tunneling therapy showed that after 37.5 months, $24 \%$ of 149 treated teeth had carious lesions in the furcation region ${ }^{15}$. Another possible complication from the tunneling technique is the occurrence of dental hypersensitivity since this surgery exposes a large number of dentinal tubules and accessory canals with the oral medium ${ }^{16}$.
The tunneling technique is considered effective only if the patient can fully cooperate with the oral hygiene techniques and participate in periodontal support therapy consultations ${ }^{16}$. The patient treated in the present case report, despite being a heavy smoker, presented a pattern of oral hygiene and motivation that allowed the tunneling technique to succeed after 12 months of follow-up. Long-term follow-ups will be necessary to determine whether, in this particular case, this technique will allow long-term survival of the dental element 46 .

\section{Final Considerations}

Although periodontal therapy of teeth with a grade III furcation lesion is not predictable, in some patients who are at risk for treatment with dental implants, periodontal tunneling therapy may be a good option as demonstrated in the present clinical case report, where it is possible to observe the therapeutic success of the tunneling technique of the lower molar performed in a heavy smoker patient ( $>20$ cigarettes per day).

\section{Referências}

1. Cazalis J, Tanabe S, Gagnon G, Sorsa T, Grenier D. Tetracyclines and chemically modified tetracycline-3 (CMT-3) modulate cytokine secretion by lipopolysaccharide-stimulated whole blood. Inflammation. 2009 Apr;32(2):130-7.

2. Siddiqui ZR, Jhingran R, Bains VK, Srivastava R, Madan R, Rizvi I. Comparative evaluation of platelet-rich fibrin versus beta-tri-calcium phosphate in the treatment of Grade II mandibular furcation defects using cone-beam computed tomography. Eur J Dent. 2016 Oct-Dec;10(4):496-506.

3. Nibali L, Zavattini A, Nagata K, Di Iorio A, Lin GH, Needleman I, Donos N. Tooth loss in molars with and without furcation involvement - a systematic review and meta-analysis. J Clin Periodontol. 2016 Feb;43(2):156-66.

4. Naujokat $H$, Kunzendorf B, Wiltfang J. Dental implants and diabetes mellitus-a systematic review. Int J Implant Dent. 2016 Dec;2(1):5.

5. Svärdström G, Wennström JL. Periodontal treatment decisions for molars: an analysis of influencing factors and long-term outcome. J Periodontol. 2000 Apr;71(4):579-85.

6. Dannewitz B, Krieger JK, Hüsing J, Eickholz P. Loss of molars in periodontally treated patients: a retrospective analysis five years or more after active periodontal treatment. J Clin Periodontol. 2006 Jan;33(1):53-61.

7. Feres M, Araujo MW, Figueiredo LC, Oppermann RV. Clinical evaluation of tunneled molars: a retrospective study. J Int Acad Periodontol. 2006 Jul;8(3):96-103.

8. Zafiropoulos GG, Hoffmann O, Kasaj A, Willershausen B, Deli G, Tatakis DN. Mandibular molar root resection versus implant therapy: a retrospective nonrandomized study. J Oral Implantol. 2009;35(2):52-62.

9. Schwendicke F, Graetz C, Stolpe M, Dörfer CE. Retaining or replacing molars with furcation involvement: a cost-effectiveness comparison of different strategies. J Clin Periodontol. 
2014 Nov;41(11):1090-7.

10. Moraschini V, Barboza Ed. Success of dental implants in smokers and non-smokers: a systematic review and meta-analysis. Int J Oral Maxillofac Surg. 2016 Feb;45(2):205-15.

11. Patel RA, Wilson RF, Palmer RM. The effect of smoking on periodontal bone regeneration: a systematic review and meta-analysis. J Periodontol. 2012 Feb;83(2):143-55.

12. Parashis AO, Anagnou-Vareltzides A, Demetriou N. Calculus removal from multirooted teeth with and without surgical access. II. Comparison between external and furcation surfaces and effect of furcation entrance width. J Clin Periodontol. 1993 Apr;20(4):294-8

13. Avila-Ortiz G, De Buitrago JG, Reddy MS. Periodontal regeneration - furcation defects: a systematic review from the AAP Regeneration Workshop. J Periodontol. 2015 Feb;86(2 Suppl): S108-30.

14. Pontoriero R, Lindhe J. Guided tissue regeneration in the treatment of degree III furcation defects in maxillary molars. J Clin Periodontol. 1995 Oct;22(10):810-2.

15. Hellden LB, Elliot A, Steffensen B, Steffensen JE. The prognosis of tunnel preparations in treatment of class III furcations. A follow-up study. J Periodontol. 1989 Apr;60(4):182-7.

16. Sonika Shakya, Shaili Pradhan. Tunneling: A treatment modality for furcation involved teeth $-A$ case report. Journal of Nepal Dental Association - JNDA | Vol 14, No 2, Aug-Dec 2014.
Recebido em : 05/06/2017

Aprovado em: 10/07/2017

Os autores declaram que não há conflitos de interesse.

\section{Corresponding author:}

Francesco Saverio Ludovichetti* DDS, Resident, University of Padova, Department of Neurosciences, Dentistry Section, Via Giustiniani, 1, 35131 Padova, Italy, Phone +39 $3408573561-$ Fax +39 0498070364 - email: f.ludovichetti@gmail.com 
Tratamento de lesão de furca grau III por tunelização em paciente fumante: Relato de caso clínico

\section{Resumo}

Objetivos: O objetivo deste trabalho é descrever um relato de caso de tratamento de molar inferior com lesão de furca grau III pela técninca de tunelização em um paciene fumante pesado. Relato de caso: Nesse estudo um paciente homem com 40 anos de idade e fumante pesado (> 20 cigarros/dia) apresentava apos o exame clinico e radiográfico uma lesão de furca grau III no elemento dentário 46. Apos uma terapia periodontal não-cirúrgica, o paciente foi tratado com a execução da tunelização da furca do dente 46 , que foi eficaz no controle da doença e na manutenção do elemento dentário após 12 meses de acompanhamento. Considerações finais: A técnica de tunelização foi eficaz no controle da doença periodontal em paciente fumante pesado, com bom padrão de higienização e de motivação, e os bons resultados clínicos se mantiveram mantiveram após 12 meses de acompanhamento.

Palavras-chave: Defeito de furca; Raspagem dental; Implante; Periodontal; Plástica. 